\title{
Laparoscopic restorative proctocolectomy with ileal pouch-anal anastomosis for ulcerative colitis and the impact of anti-tumor necrosis factor on postoperative outcomes
}

\author{
Benjamin Coquet-Reinier • S. V. Berdah
}

Published online: 24 December 2010

(C) Springer Science+Business Media, LLC 2010

First, I thank Professors Hanisch and Zioga for their interesting comments on our work. The multifactorial etiology of inflammatory bowel diseases implies that before long, their treatments will not be purely pharmacologic. Indeed, even if anti-tumor necrosis factor- $\alpha$ (anti-TNF $\alpha$ ) drugs are of major interest for their management, to date they have not proven their efficiency in reducing the restorative proctocolectomy rate in the course of ulcerative colitis [1].

Surgical treatment then is meant to be part of the therapeutic options for a long time to come. In addition, surgery also allows prevention of the most serious long-term complication of ulcerative colitis, which is neoplasia. However, it is a complex procedure, requiring a large experience in colorectal surgery and laparoscopy. It brings major consequences to patients' quality of life, including incontinence and low fertility for women [2].

As mentioned by Professors Hanisch and Zioga, our study aimed to assess the consequences of pharmacologic and surgical treatments used on the same patient. This occurrence still is frequent, given the complementarities of these treatments. Anti-TNF $\alpha$ drugs interact with inflammatory processes, interfering with immunity and wound-healing mechanisms. Questions about their safety in a possible surgical context were legitimate. Our study, taking its statistical weakness into account, seems to confirm it. Still, it seemed important to underscore the need for precautions in this multimodal strategy, sometimes using means with theoretical antagonisms.

Disclosures B. Coquet-Reinier and S. V. Berdah have no conflicts of interest or financial ties to disclose.

\section{References}

1. Aratari A, Papi C, Clemente V, Moretti A, Luchetti R, Loch M, Capurso L, Caprilli R (2008) Colectomy rate in acute severe ulcerative colitis in the infliximab era. Dig Liver Dis 40:821-826

2. Cornish JA, Tan E, Teare J, Teoh TG, Rai R, Darzi AW, Paraskevas P, Clark SK, Tekkis PP (2007) The effect of restorative proctocolectomy on sexual function, urinary function, fertility, pregnancy, and delivery: a systematic review. Dis Colon Rectum 50:128-138
B. Coquet-Reinier $(\bowtie) \cdot S$. V. Berdah

Department of Digestive Diseases Surgery, Hôpital Nord,

Marseille, France

e-mail: benjamin.coquet-reinier@ap-hm.fr 